\title{
Invariants of the Hilbert Transform for 23-Hilbert Problem
}

\section{Mazurkin Peter Matveevich}

Department of environmental engineering, Volga State University of Technology, Yoshkar-Ola, Republic of Mari El, Russian Federation

\author{
Email address: \\ kaf_po@mail.ru
}

\section{To cite this article:}

Mazurkin Peter Matveevich. Invariants of the Hilbert Transform for 23-Hilbert Problem. Advances in Sciences and Humanities.

Vol. 1, No. 1, 2015, pp. 1-12. doi: 10.11648/j.ash.20150101.11

\begin{abstract}
Process of identification of steady laws in the form of asymmetric wavelet signals is stated. Thus the wave equations with variables amplitude and the period of fluctuation are designed from the generalized invariant and its fragments. This invariant according to Hilbert is reasonable as the biotechnical law generalizing almost all known laws of distribution. The essence, structure and parameters of the biotechnical law and its fragments is in detail shown. For identification statistical data of measurements in the form of tabular model are required. Then Hilbert's 23rd problem is solved as a problem of statistical (probabilistic) modeling. At the first stage the variation of functions is reduced to conscious selection of steady laws and designing on their basis of steady wave regularities adequate to studied natural processes. At the second stage there is a consecutive structural and parametrical identification of regularities on statistical selections by the sum asymmetric wavelets. The decision 23-oh Hilbert's problems by the one and only universal algebraic wave equation, in the general form on Descartes's hypothesis where half of amplitude and the period are displayed by the biotechnical law is given. Everyone wavelet this algebraic equation contains two fundamental physical constants - the number e of time or Napier and the number $\pi$ of space or Archimedes.
\end{abstract}

Keywords: 23-oh Hilbert's Problems, Algebraic Wave, Identification, Asymmetric Wavelet Signals

\section{Introduction}

On a site http://link.springer.com/journal/208 by search on words "Invariants of the Hilbert transform for 23-Hilbert problem" appeared only two links to publications $[2,3]$. And for the words "Invariants of the Hilbert transform" we received 5860 links. As a result it is visible that invariants or Hilbert's bricks for the solution of the 23 rd problem still aren't found.

The problem of development of methods of calculus of variations (Hilbert's 23rd problem) still isn't resolved though in this direction it was much made Hilbert [4]. David Hilbert's mathematical activity can conditionally be divided into two multidirectional concepts (understanding vectors):

a) the integrated equations and physics (in a general sense, including all sciences: astronomy, biology and ecology, econometrics, technology, etc.);

b) algebraic numerical fields and invariants.

Two of these vectors of understanding unite in the theory of axiomatics of Hilbert.

Thus, the axiomatics is cornerstone of both approaches from the mathematician to the physicist-theorist (the first vector) and, on the contrary, from the experimenter to the mathematician. The approach mathematician-theorist to the development of abstract mathematics, we do not consider. On many examples (more than 100 thousand) statistical (probabilistic) modeling were convinced that the solution of the 23rd problem of Hilbert is found not in mathematics or physics separately, namely in transition from experimental physics (measurement in physics, astronomy, biology and ecology, sociology and econometrics, equipment and technology) to methods of applied mathematics.

Key to understanding classical mathematics of methodology of identification of invariants offered by us on real algebraic numerical fields as to results of multiple-factor physical measurements, the heuristic statement is: "As leading principle for Hilbert the analogy to the corresponding problems for algebraic functions from one variable served" [4].

But our invariants smooth and nonlinear steady laws are, including also asymmetric wave functions (wavelet signals) applicable to real numerical fields (statistical selections). Thus not only time, but also each physical factor can be accepted to the explaining variable.

In the beginning we will give the analysis of the generalized invariant, and then we will show methodology of identification of the sum wavelets. Historically formulas of the sum of invariants became complicated. 
For example, in the publication [6, p.77] is given the sum of the linear equations in the form of a formula

$$
\phi=\alpha_{1} \phi_{1}+\alpha_{2} \phi_{2}+\ldots+\alpha_{\mathrm{m}} \phi_{\mathrm{m}}
$$

Expression is the general result nowadays known as the main theorem of Hilbert for polynomial ideals. We refuse polynomials as they don't make physical sense, however we keep additive character of the main theorem of Hilbert. Thus sequences of algebraic forms is accepted only from one variable, and forms on a design become identical. Linear forms are given also in the book [5, p.238-239].

The linear additive design from the same modules for one explaining variable has a infinite-dimensional interval $(-\infty$; $+\infty)$. Therefore it is universal, for example, in the analysis of a row of the integers prime numbers [9]. But then mathematics and physics began to create the theories only on a positive half shaft $(0 ;+\infty)$. For example, Einstein didn't love negative numbers.

For a positive half shaft of an abscissa in $[1, \mathrm{p} .71]$ is given a formula

$$
\mathrm{Az} z^{\alpha}+\mathrm{Bz}^{\beta}+\mathrm{Cz}^{\gamma}+\mathrm{Dz}{ }^{\delta}+\text { etc. }
$$

In econometrics at different explanatory variables (2) is the product of the components becomes a form of Cobb-Douglas. Still Euler noticed that this form (2) isn't applicable for the description of fluctuations of a string. For a square form in relation to two explaining variables Hilbert offered [1, p.249] a degree invariant three in the form of expression

$$
a x_{1}^{3}+b x_{1}^{2} x_{2}+c x_{1} x_{2}^{2}+d x_{2}^{3}
$$

Under a condition the $\mathrm{x}_{1}=\mathrm{x}_{2}$ formula (3) turns into expression $\mathrm{ax}^{3}$ which can easily be generalized in the form of the steady indicative law $\mathrm{ax}^{\mathrm{b}}$.

However, the solution of a problem of further development of methods of calculus of variations [1, p.289], put by Hilbert in 1900 in the list at number 23, didn't overcome a known invariant $\mathrm{ax}^{\mathrm{b}}$. In many respects it was prevented by disputes among mathematicians. As we understand now, the generalized invariant could be revealed still by Hilbert if he paid attention to Laplace's steady exponential law $\exp (-\mathrm{cx})$. It is the law it is widely known also in physics (Mandelbrot's law), biology (Zipf's law) and econometrics (Pareto's law).

The scalar product is indicative of the law $a x^{b}$ on the modified law of Laplace $\exp (-\mathrm{cx})$, (we have introduced the parameter d) we called biotechnological law.

\section{Biotechnical Law and Its Features}

Heuristically (in substantial sense) the biotechnical law is formulated as follows: in the processes of life and evolution of biological and biogenic objects over time no action is equal to counteraction.

Equality of forces of action and counteraction (under the third law of Newton) is observed in time only at the transition moment from growth to dying off, that is the case is shown as private (one-stage in time) [26].

The law of spatial interaction offered by us, without time, is briefly formulated so: Action isn't equal to counteraction. The name "biotechnical law" offered by us indicates skill of life (techne - skill, bio - life), that is this steady law (the generalized invariant according to Hilbert) is shown in those objects of research in which to some extent there is a life at the present or there are its manifestations in the past (for example, wood and wood materials). Therefore in all abiotic objects, including and star systems, skill of life has to be shown.

For engineering ecology, rational environmental management, arrangement of the natural objects, territorial managing and other types of ecological and economic activity connected with natural objects and economic systems, the sum of forces of action and counteraction making a measure of interaction of mankind with the nature passes into the general principle of the academician V.I. Vernadsky.

He claimed that all ecological niches on Earth remain, during regular change of the biosphere and separate biocenoses with others, filled and the total mass of the biosphere authentically doesn't change. However the last geological researches showed that, for more than three billion years, the biosphere of Earth strongly changed and on biomass. In our opinion, this lump of the biosphere during its evolution forms a variable power impulse of life on the planet Earth. Once again we will emphasize that we accept the direction of forces of interaction in the form of an arrow of time of S. Hawking.

Therefore the biotechnical law defines change only of scalar size of forces of interaction, without affecting the direction of these forces.

Thus, the biotechnical principle assumes in science unconditional transition from anthropocentrism to biocentrism. The person is only part of the nature therefore he has to proportion the action on the nature to opportunities of surrounding environment. For this purpose he has to learn to reveal steady regularities.

Statistical research and modeling is subjected to only the second type of change forces of interaction is an experimental study of the changes of some physical quantities, i.e. the scalar values of these interaction forces. All such measurements form numerical fields or statistical tables.

Change of the direction of forces (for example, succession of an ecosystem or revolutionary influence of action on an ecological mode and a territory landscape) in this article isn't considered and therefore in the majority of examples receives only substantial, and only initially set hypothetical, an explanation. In other words, for a considered numerical field of the direction of forces have to be uniform.

From such comparison we can conclude that the biotechnical law considers, first of all, a quantitative ratio of forces of action and counteraction.

Thus has to be in advance (before statistical modeling) it is known that upon transitions from one cycle to another there are no changes of the direction of these interacting forces. On the basis of application of the biotechnical law in each case of researches high-quality (heuristic) and quantitative (statistical) interpretation is carried out.

It is possible to generalize, claiming that where there is an 
interaction, there is also a manifestation of the biotechnical law.

Now, on the basis of many other scientific works, we approve the bigger: where there is a manifestation of the biotechnical law, there probably (at least fragmentary) studying of a real cycle of uniform interaction taking into account steady laws and properties of an ideal cycle.

\section{General Equation of Biotechnical Law}

Interaction two multidirectional, that is counteracting, forces in one phenomenon or process it is possible to describe a formula

$$
\mathrm{y}=\mathrm{y}_{1}(\mathrm{x}) \otimes \mathrm{y}_{2}(\mathrm{x})
$$

where $y$ - general force of interaction (value of force),

$\mathrm{x}$ - interaction factor, in particular time $\mathrm{t}$,

$\mathrm{y}_{1}(\mathrm{x})$ - action force,

$\otimes$ - sign of a type of process of interaction,

$\mathrm{y}_{2}(\mathrm{x})$ - counteraction force.

Here the formula of the biotechnical law acts as multiplicative mix of two components expressed in the form of various types of steady laws of distribution (two identical laws are a rarity, not characteristic for the deformed cycles).

If change of values of two forces casual and independent, it is possible additive $(+,-)$ interaction type, that is at independence two component of the equation (4) occurs algebraic addition or subtraction of two forces. At weak or strong interrelation of values of forces $\mathrm{F}^{+}$and $\mathrm{F}^{-}$(for example, at action resistance grows it is accelerated) the type of interaction [26] is accepted multiplicative $(\cdot, /)$.

Apparently, other, more difficult mathematical (quantitative) ratios between interaction forces are possible also, however for identification of fragments of a cycle on experimental (or not experimental, but registered) to data in many cases of statistical modeling the specified four actions of algebraic transformations are sufficient.

Most often function of action is characterized by the indicative law $\mathrm{y}_{1}(\mathrm{x})=\mathrm{ax}^{\mathrm{b}}$, and counteraction is expressed by the law of exponential death of type $y_{2}(x)=\exp \left(-c x^{d}\right)$, where: a,c - activities; b,d - intensity of action and counteraction.

For many natural phenomena multiplicative association (in one point of space always joint events) actions therefore the biotechnical law is most widespread in a type of the equation is characteristic

$$
y=a x^{b} \exp \left(-c x^{d}\right)
$$

In a mathematical design (5) quantitative expressions of the biotechnical law are available two the steady laws differing on types in the form of components of statistical regularity, - they are steady laws of growth and recession (death).

Thus on the same object both of these processes of growth and death happen in common, that is in interaction forces of growth and death are at the same time shown.
During identification of an algebraic formula of the biotechnical law constantly (a priori and a posteriori during modeling) it is necessary to ask a question: as these forces arise and why there is a deformation of an ideal cycle in the real phenomenon (during measurements before the researcher passes process as discrete sequence of the cause and effect phenomena).

Other algebraic designs of the general equation (5) which were considered by us are possible also, but they are a little shown in the phenomena and processes.

Habitual for us mathematical formulas most often represent designs from various symbols connected among themselves by algebraic or other functional relations.

Symbols can make functionally any sense. Main constructive communication between elements of mathematical models is considered.

At the same time there are steady laws of physics, chemistry and other natural sciences in which symbols of mathematical structures have the accurate semantic contents. The same is the design of the formula (5).

Much images of a material thing in the form of drawing or the drawing are habitual. Ideal object what the mathematical structure in the form of an algebraic formula (5) is, it isn't really similar to the mechanical car.

For receiving difficult designs we will write down a formula (5) with the same parameters

$$
\mathrm{y}=\mathrm{a}_{1} \mathrm{x}^{\mathrm{a}_{2}} \exp \left(-\mathrm{a}_{3} \mathrm{x}^{\mathrm{a}_{4}}\right),
$$

where number of parameter of additive model can be of great importance. Equation (6) is in fact a formal machine.

Therefore, by analogy to the subject and functional analysis of a thing, the functional description of elements of statistical model (6) is provided in table 1 . At a formula (6) there is a fundamental physical constant [25] e $=2,71 \ldots$.

Therefore the biotechnical law in symmetric record

$$
y=a_{1} x^{a_{2}} \cdot e^{-a_{3} x^{a 4}}
$$

on a design characterizes a scalar product of two forces in the spatial phenomena or processes concerning time on Napier's number $\mathrm{e}=2,71 \ldots$, that is gives scalar change of the parameter (factor) of any phenomenon or process in time. Formula (7) shows the simultaneous action of countervailing forces, for example, growth and death (decay). Explanatory variable can be not only time, but also any other factor. Many factors of a phenomenon or process is to conduct a factor analysis.

Table 1. Description of structure and functions of a formula (6) of the biotechnical law.

\begin{tabular}{ll}
\hline $\begin{array}{l}\text { Constructive } \\
\text { elements (carriers) }\end{array}$ & $\begin{array}{l}\text { Technical functions of constructive elements in } \\
\text { their hierarchical sequence }\end{array}$ \\
\hline $\begin{array}{l}\mathrm{E}-\text { object in the } \\
\text { form of a formula } \\
(6)\end{array}$ & $\begin{array}{l}\mathrm{F} \text { - unambiguous (or multivalued statistical) display } \\
\text { the values of } \mathrm{x} \text { in } \mathrm{y} ; \mathrm{F}^{\prime} \text { - at numerical sets }\{\mathrm{x}\} \\
\text { and }\{\mathrm{y}\} \text { identification of object of } \mathrm{E} \text { on required values } \\
\text { of parameters } \mathrm{a}_{1} \ldots \mathrm{a}_{4} \text { of model (6) }\end{array}$ \\
$\mathrm{V} 1$ - value $\mathrm{x}$ & $\mathrm{F}^{\prime \prime}$ - at set $\{\mathrm{y}\}$ and $\mathrm{a}_{1} \ldots \mathrm{a}_{4}$ restoration of some values \\
\hline
\end{tabular}




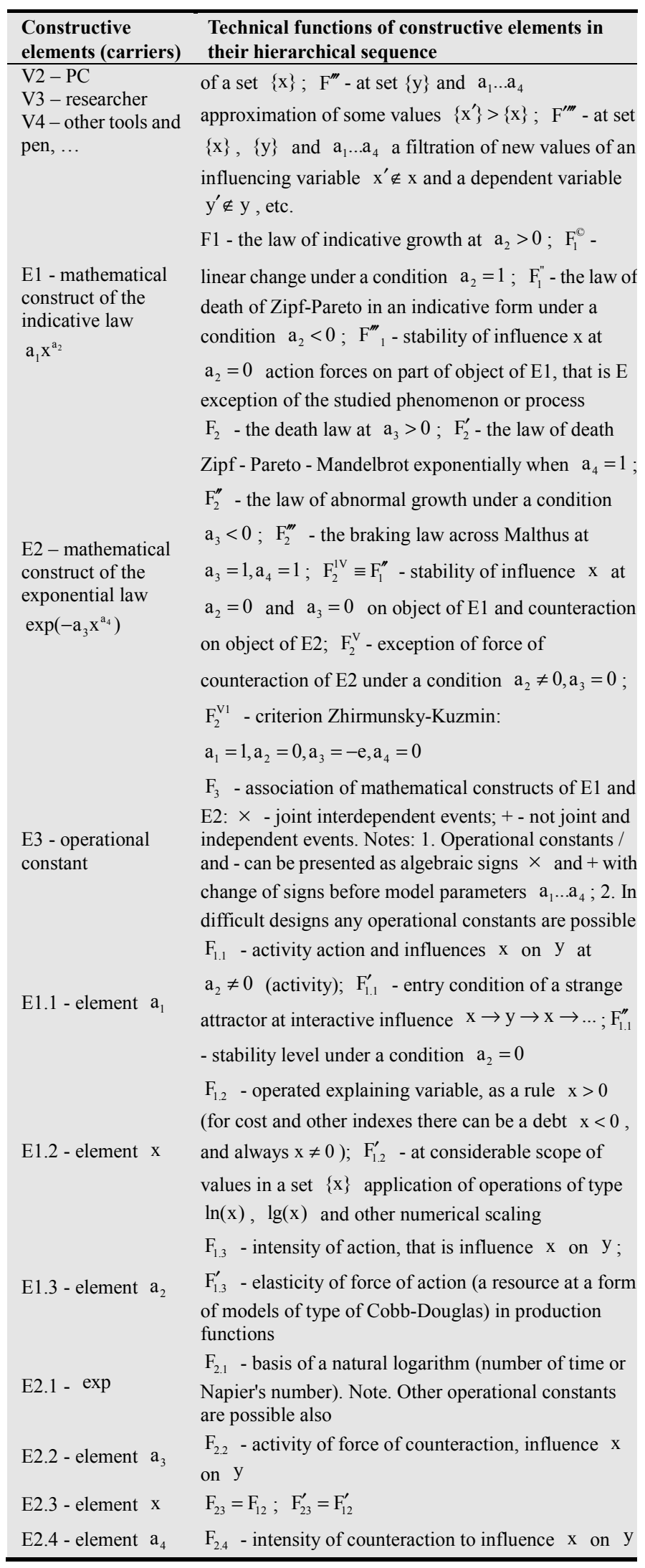

Notes: 1) parameters $a_{1} \ldots a_{4}$ can depend from $x$, that is can be $a_{1}=f_{1}(x)$,

$\mathrm{a}_{2}=\mathrm{f}_{2}(\mathrm{x}), \mathrm{a}_{3}=\mathrm{f}_{3}(\mathrm{x}), \mathrm{a}_{4}=\mathrm{f}_{4}(\mathrm{x})$;

2) the element $x$ can be derivative of other variables, that is $\mathrm{x}=\phi\left(\mathrm{x}_{1}, \mathrm{x}_{2}, \ldots\right)$;

3) the indicator of $y$ can be the generalized criterion of type $y=\varphi\left(y_{1}, y_{2}, \ldots\right)$.

\section{Ideal Form of the Biotechnical Law}

The ideal form appears not only in designs of cars and the equipment, as well as in natural works in the form of plants and animals. It can be and at mathematical formulas.

The natural and technological phenomena and processes have to be brought as it is possible closer to ideal laws of distribution.

Equality of all parameters of model to zero $\mathrm{a}_{1}=0, \mathrm{a}_{2}=0$, $a_{3}=0$ and $a_{4}=0$ doesn't give an ideal form of the biotechnical law (6). It is enough even to accept $a_{1}=0$ as all formula of the biotechnical law (6) or (7) completely vanishes.

Therefore the first parameter (6) can't matter "zero".

The ideal form of biotechnological law does not work and in other cases equal the remaining three parameters of the model (6) to zero, for example:

1) $a_{2}=0$, then $y=a_{1} \exp \left(-a_{3} x^{a_{4}}\right)$, that is, it turns the death law in a full form which differs from Laplace's well-known law and Zipf-Pareto-Mandelbrot $y=a_{1} \exp \left(-a_{3} x\right)$ that the fourth parameter of intensity of death is added;

2) $a_{3}=0$, then $y=a_{1} x^{a_{2}}$, that is, it turns out the well-known law of exponential growth (similarly obtain under the conditions $\mathrm{a}_{3}=0$ and $\mathrm{a}_{4}=0$ );

3) $\mathrm{a}_{4}=1$, then this case $\mathrm{y}=\mathrm{a}_{1} \mathrm{x}^{\mathrm{a}_{2}} \exp \left(-\mathrm{a}_{3} \mathrm{x}\right)$ turns studied regularity into the biotechnical law in the simplified form;

4) $a_{2}=0$ and $a_{3}=0$, then $y=a_{1}$, that is the law (6) turns into constant value of a studied indicator, thus for a short period of changes isn't present therefore influence of a variable on an indicator is absent.

From this it follows that the ideal form of the biotechnical law is reached only when all parameters of model (6) are equal to unit, that is such only case when conditions are met is accepted $\mathrm{a}_{1}=1, \mathrm{a}_{2}=1, \mathrm{a}_{3}=1$ and $\mathrm{a}_{4}=1$. Any other option when at least one of parameters of model isn't equal to unit, and is a real number, leads to any known steady law of distribution, for example, to malthusian growth with braking, to Rayleigh's distribution, etc.

We will write down a formula of the biotechnical law (6) with single coefficients in a look

$$
y=x \exp (-x),
$$

which really is an ideal form of the biotechnical law and therefore has remarkable property.

The power impulse as an indicator while is a little applied in science, first of all because of its insufficient quantitative study. From mathematics it is known that exact value of integral from (8) is equal to unit, that is

$$
\int_{0}^{\infty} \mathrm{x} \exp (-\mathrm{x})
$$

Then the power impulse of rather ideal form of the biotechnical law will be always equal to unit, that is under a curve (8) area is equal to unit. 


\section{Special Cases of the Biotechnical Law}

All known science smooth laws of distributions are special cases of biotech law:

1) $y=a_{1}$ at $a_{2}=0, a_{3}=0$ - lack of influence of a variable on an indicator;

2) $y=x$ at $a_{1}=1, a_{2}=1, a_{3}=0$ - the identity, variable is an indicator;

3) $y=a_{1} x$ - proportional influence $x$ on $y$ at $\mathrm{a}_{2}=1, \mathrm{a}_{3}=0$;

4) $y=x \exp (-x)$ - ideal biotechnical law, $a_{1}=1$, $\mathrm{a}_{2}=1, \mathrm{a}_{3}=1, \mathrm{a}_{4}=1$;

5) $y=a_{1} x \exp (-x)$ - Malthusian growth with braking $\mathrm{a}_{2}=1, \mathrm{a}_{3}=1, \mathrm{a}_{4}=1$;

6) $y=a_{1} x \exp \left(-a_{3} x\right)-$ Rayleigh's distribution at $\mathrm{a}_{2}=1, \mathrm{a}_{4}=1$;

7) $y=a_{1} x \exp \left(-a_{3} x^{2}\right) \quad-$ Rayleigh's distribution at $\mathrm{a}_{2}=1, \mathrm{a}_{4}=2$;

8) $y=a_{1} x^{a_{2}}-$ allometric growth at $a_{3}=0$;

9) $y=a_{1} x^{-a_{2}}$ - exponential law Zipf-Pareto, $a_{3}=0$;

10) $y=a_{1} \exp \left(-a_{3} x\right)$ - Laplace's law (in mathematics), Mandelbrot (in physics), Zipf (in biology) and Pareto (in econometrics) for $\mathrm{a}_{2}=0, \mathrm{a}_{4}=1$;

11) $y=a_{1} \exp \left(-a_{3}(x-\bar{x})^{2}\right)-$ Gauss-Laplace's law of normal distribution under conditions $\mathrm{a}_{2}=0, \mathrm{a}_{4}=2$, where $\overline{\mathrm{x}}$ - average value (mathematical expectation) of a variable $\mathrm{x}$; here $\mathrm{a}_{1}=1 /(\sigma \sqrt{2 \pi}), \mathrm{a}_{2}=1 /\left(2 \sigma^{2}\right)$, where $\sigma \quad$ - $\mathrm{a}$ deviation an average square;

12) $y=a_{1}\left(1+a_{5} \exp \left(-a_{3} x\right)\right)^{-1}$ - the Pearl law at $\mathrm{a}_{2}=0, \mathrm{a}_{4}=1$ and addition $\mathrm{a}_{5}$ to mathematical construct of force of counteraction of other factors;

13) $y=a_{1}\left(a_{5}+\exp \left(a_{6} \exp \left(-a_{3} x\right)\right)\right)^{-1}$ - law A.F. Kamenev on the basis of complication of force of counteraction;

14) $y=a_{1}\left(1-\exp \left(-a_{3} x\right)\right)^{a_{5}}$ - the law Mitcherlich I for the course of growth of forest stands, as officially approved regression model for forestry specialists and foresters;

15) $y=x^{a_{2}}\left(a_{5}+a_{6} x^{a_{2}-1}+a_{7} x^{a_{2}}\right)^{-1}$ - Yoshid's II law for $a$ course of growth of forest stands, at $a_{1}=1$ and replacement of function of counteraction by a three-member formula; this law is most exact for some forest conditions, however it is difficult to explain substantially;

16) $y=\pi a_{1}\left(a_{1}^{2}+(x-b)^{2}\right)^{-1}$ - Cauchy's distribution at $a_{2}=0$ and other form of force of counteraction, where $b$ the parameter defining at the same time value of mode and median;

17) $\mathrm{y}=\mathrm{a}_{1} \exp (-\mathrm{x}) \exp \left(-\mathrm{a}_{3}(\mathrm{x}-\overline{\mathrm{x}})^{2}\right) \quad-\quad$ lognormal distribution when value $\mathrm{x}$ in force of action is replaced on $\exp (\mathrm{x})$, and $\mathrm{a}_{2}=-1$;
18) $\mathrm{y}=\mathrm{a}_{1} \mathrm{x}^{2} \exp \left(-\mathrm{a}_{3} \mathrm{x}^{2}\right)$ - Maxwell's distribution at $\mathrm{a}_{2}=2, \mathrm{a}_{4}=2, \mathrm{a}_{1}=(\sqrt{2 / \pi}) \alpha^{-3}, \mathrm{a}_{3}=1 /\left(2 \alpha^{2}\right)$, where $\alpha$ distribution parameter, $\hat{\alpha}=0.6267 \overline{\mathrm{x}}$;

19) $y=a_{1} \exp \left(-a_{3} x^{2}\right)$ - a number of Gram-Charlier of the type A, sometimes used for studying of ranks of distribution of values of taxation indicators of sets of trees, and $a_{1}=1 / \sqrt{2 \pi}$, $\mathrm{a}_{3}=1 / 2, \mathrm{a}_{2}=0, \mathrm{a}_{4}=2$;

20) $y=a_{1} \exp \left(-a_{1} x\right) \quad-\quad$ distribution exponential, $\mathrm{a}_{2}=0, \mathrm{a}_{3}=\mathrm{a}_{1}, \mathrm{a}_{4}=1$;

21) $y=a_{1} x^{a_{2}} \exp \left(-a_{3} x\right)-$ Erlang distribution at parameters $a_{1}=(n \mu)^{n} / д(n), a_{2}=n-1, a_{3}=n \mu$, where $\mathrm{n} \geq 1$ и $\mu>0$ - distribution parameters, $Г(\mathrm{n})$ - gamma function;

22) $y(x=m)=a_{1} \lambda^{a_{2}} \exp (-\lambda)$ - Poisson's distribution at parameters $\mathrm{a}_{1}=\mathrm{m} !, \mathrm{a}_{2}=\mathrm{m}, \mathrm{a}_{3}=1, \mathrm{a}_{4}=1, \quad$ where $\mathrm{m}=0,1,2, \ldots$ whole non-negative numbers;

23) $y=a_{1} \exp \left(-a_{3} t^{2}\right)$ - distribution normal standardized at parameters $\mathrm{a}_{1}=1 / \sqrt{2 \pi}, \mathrm{a}_{2}=0, \mathrm{a}_{3}=1 / 2, \mathrm{t}=(\mathrm{x}-\overline{\mathrm{x}}) / \sigma$, where $\sigma$-deviation average square;

24) $y=a_{1} x^{a_{2}} \exp \left(-a_{3} x\right)$ - the biotechnical law in the simplified form at $a_{4}=1$;

25) $y=a_{1} x^{a_{2}} \exp \left(-a_{3} x^{a_{4}}\right)$ - the biotechnical law (the generalized invariant);

26) $y=a_{1}+a_{5} x$ - the law sum not influences of an influencing variable and linear distribution at parameters $\mathrm{a}_{2}=\mathrm{a}_{3}=\mathrm{a}_{4}=0$ and $\mathrm{a}_{6}=1, \mathrm{a}_{7}=\mathrm{a}_{8}=0$;

27) $y=a_{0}+a_{1} x^{a_{2}}-$ Nikitin's law for the course of growth of forest stands at $\mathrm{a}_{3}=0$;

28) $y=a_{1}-a_{5} \exp \left(-a_{7} x^{a_{8}}\right)-$ Weibull's distribution at $\mathrm{a}_{2}=\mathrm{a}_{3}=\mathrm{a}_{4}=0$ and $\mathrm{a}_{6}=0$;

29) $y=a_{1} \pm a_{5} x^{a_{6}} \exp \left(-a_{7} x^{a_{8}}\right)$ - full law of change of $a$ half-cycle of fluctuation;

30) $\mathrm{y}=\mathrm{a}_{1} \mathrm{x}^{\mathrm{a}_{2}} \exp \left(-\mathrm{a}_{3} \mathrm{x}^{\mathrm{a}_{4}}\right)+\mathrm{a}_{5} \mathrm{x}^{\mathrm{a}_{6}} \exp \left(-\mathrm{a}_{7} \mathrm{x}^{\mathrm{a}_{8}}\right)$ - the sum of two biotechnical laws for identification of the deterministic behavior of biological objects.

\section{Identification of the Biotechnical Law}

\subsection{Method of Identification}

Process of identification of steady regularities of [8, 17-19, 24-28, 34] different forms containing in invariants of type (6), is presented as process of the solution of a problem of statistical (probabilistic) modeling by asymmetric wavelet signals on dynamic ranks of measurements. Further the methodology of identification of steady laws of determined or wave dynamics of any process by wave functions with variables amplitude and fluctuation frequency is shown.

This section is given as the decision 23-oh Hilbert's 
problems by the one and only universal algebraic wave equation in the general form offered by the author and by that the hypothesis and Descartes's known concept is proved. Euler's hypothesis of universality of the sum of trigonometric functions for the description of dynamics of natural processes is proved also.

The error of measurements or quantitative representations by drawing up a numerical field, i.e. the table initial data becomes criterion (a quantitative measure) identifications. For example, prime numbers and their ranks $[9,11,12,20-23,30]$ have no measurement error: they are absolutely reliable, sound and reliable. Other types of basic data have a different error. Thus, mathematical numerical objects - the best for identification of laws invariants.

On the second place there are precision measurements in astronomy and physics [10, 13, 14, 29, 31, 32], equipment and technology [16], other areas of science. On the third place there are biological objects $[17,18]$, and their behavior has accurately being shown oscillatory character in adaptation to external influences therefore the linear and linearized models at all don't suit biologists. The highest errors have social and economic measurements $[15,28,33]$ because of their high subjectivity. By us it was proved what exactly the analysis of the weak communications rejected at linear modeling, and application of arithmetic-mean factorial communication under Gauss-Laplace's law (normal distribution), gives new scientific ideas and the subsequent scientific and technical decisions (for 15 years with participation of students was taken out nearly 100 patents for inventions of the Russian Federation).

The literature analysis on mathematical statistics showed that in approximation the linear model or an algebraic polynomial not making physical sense is pretty often applied. It occurs because linear model invariant to any type of distribution and even to negative values of an explaining variable, including obviously non-Gaussian structure. Thus the linear model type (1) is applicable and to data of measurements with variable dispersion [26]. It is applied by us at the beginning of procedures of statistical modeling, and then the model becomes complicated to the design containing the biotechnical law or its fragments.

Identification on a numerical field (tabular model) includes the following stages:

1) heuristic identification of an essence of the studied phenomenon or process by results of measurements and the analysis of tabular model (aprioristic information) and the subsequent judgment during design identification at statistical one-factorial regularity on its additive components (posteriori information);

2) structural identification of each one-factorial mathematical function in the general model as the sums of invariants in the form of asymmetric wavelet signals (we don't provide methodology of multiple-factor modeling in article);

3) parametrical identification increased on separate invariants of the structure each steady statistical regularity in the program environment CurveExpert-1.40 (http://www.curveexpert.net).

\subsection{Identification Heuristic}

She assumes knowledge of an object of research therefore transition from physics to mathematics, and not the reverse here is important. The principal heuristic value gets the set numerical field, as a rule, made out by results of measurements or generalizing representations in the form of the table. In it all substantial sense (heuristics) and understanding (concept) of the author of measurements of deep sense of experiment is implicitly concluded.

The error of measurements by drawing up a numerical field, i.e. the table initial data becomes criterion (a quantitative measure) identifications. Thus this error is considered at a stop of the automated process of identification.

We refused long ago methods of approximation and, respectively, at all we don't apply the statistics program from the Excel environment.

In technology of identification the first stage (a variation of functions) is excluded from the theory of approximation, steady laws are in advance set as invariants. From them as from bricks it is possible to create various mathematical constructs.

Use in each concrete example of statistical (probabilistic) modeling of this or that steady law (according to their table 2 of everything seven) demands preliminary heuristic judgment of the maintenance of a problem of modeling.

Thus, at the heuristic level the $23 \mathrm{rd}$ problem of Hilbert is still insufficiently formalized by us (because of an illegibility of the formulation of the problem). But it was completely solved at the structural and parametrical levels of the analysis and synthesis. The variation of functions is reduced to conscious selection of steady laws and designing on their basis adequate to the studied natural processes of steady wave regularities. Therefore the first stage is excluded from the existing theory of identification.

In the future the automated designing of one-factorial models for any tabular data (numerical matrixes) on multiple-factor measurements is supposed. It will repeatedly reduce labor input of statistical modeling. Thus the multiple-factor analysis of data is made by the binary relations on the sum wavelets.

\subsection{Identification Structural}

Descartes assumed existence of the one and only algebraic equation suitable as the general version of the decision for any types of the integrated equations.

Hilbert dreamed of invariants from which as from bricks this universal equation will gather.

Our universal invariants are given in table 2. They are grouped in the principle "from simple to difficult" and complication of a form of steady laws in the form of the biotechnical law comes to the end with the generalized invariant.

In fact, fragments and the biotechnical law are "Hilbert's bricks" for construction, during process of structural and parametrical identification, an additive design of the required statistical determined or wave model. 
Invariants of oscillatory indignations in the form of asymmetric wavelet signals also include constructs from table 2 as amplitude (half) and a half-cycle. All most meeting invariants (fragments) are shown in table 2. Their operational constants "+" or "-" can be ahead located. Six steady laws of distribution are special cases of the biotechnical law shown in the bottom of table 2. In the law name the word "biotechnical" means that we adhere to V. I. Vernadsky's ideas about space function of life. It is proved in [21] that Fibonacci's number is certain "relative" of a number of positive prime numbers.

If are known heuristic background of formation of a numerical field (tabular model), semantic interpretation of each wavelet signal at which wavelet (wave function) in the design is quite possible contains these or those mathematical invariants from table 2.

Table 2. Mathematical constructs (initial invariants) for drawing up statistical model.

\begin{tabular}{|c|c|}
\hline $\begin{array}{l}\text { Fragments without background } \\
\text { of the studied phenomenon or } \\
\text { process }\end{array}$ & $\begin{array}{l}\text { Fragments with background of } \\
\text { the studied phenomenon or } \\
\text { process }\end{array}$ \\
\hline $\begin{array}{l}\mathrm{y}=\mathrm{ax}-\text { the law of linear growth } \\
\text { or recession (at a negative sign } \\
\text { before the right side of a formula of } \\
\text { linear change) }\end{array}$ & $\begin{array}{l}\mathrm{y}=\mathrm{a}-\text { the law not influences of } \\
\text { the accepted explaining variable on } \\
\text { an indicator which has own } \\
\text { background of values }\end{array}$ \\
\hline $\begin{array}{l}y=a x^{b}-\text { the law of indicative } \\
\text { growth (the law of indicative death } \\
y=a x^{-b} \text { isn't steady, because of } \\
\text { infinity of an indicator at zero value } \\
\text { of an explaining variable) }\end{array}$ & $\begin{array}{l}y=a \exp ( \pm c x)-\text { Laplace's law in } \\
\text { mathematics (Zipf in biology, } \\
\text { Pareto in economy, Mandelbrot in } \\
\text { physics) the exponential growth or } \\
\text { death concerning which Laplace } \\
\text { created methodology of operator } \\
\text { calculation }\end{array}$ \\
\hline $\begin{array}{l}y=a x^{b} \exp (-c x)-\text { the } \\
\text { biotechnical law in the simplified } \\
\text { form (P. M. Mazurkin) when } \\
\text { indicative growth gradually receives } \\
\text { exponential braking }\end{array}$ & $\begin{array}{l}y=a \exp \left( \pm c x^{\mathrm{d}}\right)-\text { the law of } \\
\text { exponential growth or death in a full } \\
\text { form (design) which has intensity of } \\
\text { change of the explaining variable, } \\
\text { not equal to unit (P. M. Mazurkin) }\end{array}$ \\
\hline \multicolumn{2}{|c|}{$\begin{array}{l}y=a x^{b} \exp \left(-c x^{d}\right)-\text { the biotechnical law, the general for six constructs (P. } \\
\text { M. Mazurkin) }\end{array}$} \\
\hline
\end{tabular}

All known laws of distribution are special cases of the biotechnical law that is shown in manuals $[26,34]$ and above in article.

For example, the Gauss law (so-called normal distribution) will register from the law exponential (on the basis with time number e) death according to table 2 with addition with the fourth parameter $f$ at model in the form of a formula

$$
y=a \exp \left(-c(x-f)^{d=2}\right), b=0, f=\tilde{x},
$$

where $\tilde{\mathrm{x}}$ - value of an influencing variable at a maximum of a dependent indicator.

Steady laws and regularities on their basis make an equation choice for the subsequent identification on statistical data (numerical fields) quite intelligent and therefore probabilistic modeling remains only by casual search by the program CurveExpert environment of values of parameters at required model.

Therefore from the existing theory of identification the first stage (a choice of casual structure of the equation) is excluded and remains only the second stage - casual identification of values of parameters of required algebraic model.

Identification of structure of model is carried out by processing of basic data so:

- in the beginning it is necessary to reveal the determined nonlinear regularities;

- then to supplement these trend regularities with oscillatory indignations.

\subsection{Identification Parametrical}

It is executed in a software environment CurveExpert-1.40 and our information identification technology used by students (future bachelors and masters), as well as graduate and doctoral students.

On many examples the methodology of structural and parametrical identification is in detail shown in [8-34].

The choice of structure of required model which is the algebraic decision on Descartes for an unknown antiderivative on the wave equations having variables amplitude and a half-cycle (frequency half as inverse value of a half-cycle) oscillatory indignation of object of research, that is his behavior in time, is carried out from the steady laws (invariants) provided in table 2.

Process of parametrical identification automatically stops on an achievement condition at parameters of model of some minimum increment and stops the user at achievement by designed statistical model of an error of measurements for the set numerical field.

Therefore the need for stages of building of required model new components depends on an error of measurements at experiments. In this regard the author of basic data always needs to estimate an error of measurements of own experiments.

\section{Levels of Adequacy of Regularities}

Intervals of change of coefficient of correlation as measures of adequacy to the identified statistical model are given in table 3 .

Table 3. Levels of narrowness of factorial communications.

\begin{tabular}{|c|c|c|c|c|}
\hline \multirow[b]{2}{*}{$\begin{array}{l}\text { Interval of coefficient of } \\
\text { correlation }\end{array}$} & \multicolumn{4}{|c|}{ Nature of narrowness of communication between factors } \\
\hline & $\begin{array}{l}\text { the existing } \\
\text { classification }\end{array}$ & $\begin{array}{l}\text { scale for technical } \\
\text { measurements }\end{array}$ & $\begin{array}{l}\text { scale for precision } \\
\text { measurements }\end{array}$ & $\begin{array}{l}\text { scale for genetic engineering and ranks } \\
\text { of the } \\
\text { integers prime }\end{array}$ \\
\hline $\begin{array}{c}1 \\
0.999 \ldots 1.0000 \\
0,99 \ldots 1,000 \\
0,95 \ldots 0,99 \\
\end{array}$ & strong communication & $\begin{array}{l}\text { unambiguous } \\
\text { the strongest }\end{array}$ & $\begin{array}{l}\text { the unambiguous } \\
\text { the almost unambiguous } \\
\text { the superstrong }\end{array}$ & $\begin{array}{l}\text { the unambiguous } \\
\text { the almost unambiguous } \\
\text { the extremely strong } \\
\text { the superstrong }\end{array}$ \\
\hline
\end{tabular}




\begin{tabular}{|c|c|c|c|c|}
\hline \multirow[b]{2}{*}{$\begin{array}{l}\text { Interval of coefficient of } \\
\text { correlation }\end{array}$} & \multicolumn{4}{|c|}{ Nature of narrowness of communication between factors } \\
\hline & $\begin{array}{l}\text { the existing } \\
\text { classification }\end{array}$ & $\begin{array}{l}\text { scale for technical } \\
\text { measurements }\end{array}$ & $\begin{array}{l}\text { scale for precision } \\
\text { measurements }\end{array}$ & $\begin{array}{l}\text { scale for genetic engineering and ranks } \\
\text { of the } \\
\text { integers prime }\end{array}$ \\
\hline $0,90 \ldots 0,95$ & \multirow{7}{*}{ weak communication } & \multirow{7}{*}{$\begin{array}{l}\text { the strong } \\
\text { average } \\
\text { rather weak } \\
\text { the weak } \\
\text { the weakest } \\
\text { there is no communication }\end{array}$} & \multirow{7}{*}{$\begin{array}{l}\text { the strongest } \\
\text { the strong } \\
\text { average } \\
\text { rather weak } \\
\text { the weak } \\
\text { the weakest }\end{array}$} & the strongest \\
\hline $0,7 \ldots 0,9$ & & & & the strong \\
\hline $0,5 \ldots 0,7$ & & & & average \\
\hline $0,3 \ldots 0,5$ & & & & rather weak \\
\hline $0,1 \ldots 0,3$ & & & & the weak \\
\hline $0,0 \ldots 0,1$ & & & & the weakest \\
\hline 0 & & & & \\
\hline
\end{tabular}

The existing scale of quantification of narrowness of communication between the accepted factors (there is no communication, weak and strong communication) is very rough and even primitive.

By us it is offered for technical experiments in which the error of measurements doesn't exceed $5 \%$, other scale (the third column of table 3 ). However it became clear that it is also not enough this scale of levels of adequacy.

For many natural objects and results of precision physical measurements it was necessary to enter two more intervals of level of adequacy on the fourth column of table 3 . It was executed by us only when modeling distributions of ranks of prime numbers $[20-23,30]$. And for genetic engineering it was necessary to enter one more level of adequacy which was open by us only for ranks of the whole prime numbers $[9,11,12]$.

\section{Statistical Identification}

\subsection{The Modeling Concept on Statistical Selections}

Statistical selection - this multiple-factor numerical field issued in the form of tabular model. This definition it significantly differs from tables of statistical researches as only numerical selections are applied to modeling.

And optional all cages of the table have to be the filled numbers. However cages have to have quantitative, uniform on the accepted set of factors, values. Thus the tabular model optional has heuristic explanations. As a rule, authors of measurements, providing in the publications results of researches in the form of tables of data, as a rule, yield incorrect substantial interpretation. Therefore it is necessary to provide in publications primary data of measurements, instead of transformed by results of application of classical mathematical statistics data.

This phenomenon of formalization is connected with that the table of results of measurements even if it is made by authors correctly, can't be substantially comprehended without carrying out the factorial analysis (in article it isn't provided) with mathematical modeling of communications between couples of factors for identification of binary communications.

Then primary there is a tabular model (an initial numerical field) which is estimated on an error of measurements, and secondary - the required difficult algebraic equation (in the sense of Descartes), made of table 2 invariants (that is Hilbert's bricks). Primary data invariant in relation to different models.

We called this process of identification - statistical identification.

The antiderivative in the form of the unknown integrated equation becomes not necessary though, maybe, someone and will manage to receive integrals on our models. It would be great creation, as well as Maxwell's general equations for electromagnetism.

\subsection{Determined Model}

Generally not the wave determined model (for example, a trend or a tendency) contains the sum of two biotechnical laws and receives a type of the equation

$$
\begin{aligned}
& \mathrm{y}_{\mathrm{T}}=\mathrm{y}_{\mathrm{T} 1}+\mathrm{y}_{\mathrm{T} 2}, \quad \mathrm{y}_{\mathrm{T} 1}=\mathrm{a}_{1} \mathrm{x}^{\mathrm{a}_{2}} \exp \left(-\mathrm{a}_{3} \mathrm{x}^{\mathrm{a}_{4}}\right), \\
& \mathrm{y}_{\mathrm{T} 2}=\mathrm{a}_{5} \mathrm{x}^{\mathrm{a}_{6}} \exp \left(-\mathrm{a}_{7} \mathrm{x}^{\mathrm{a}_{8}}\right),
\end{aligned}
$$

where $y_{\mathrm{T}}-\mathrm{a}$ trend (tendency) of a dependent factor (indicator), $\mathrm{x}$ - an explaining variable, $\mathrm{a}_{1} \ldots \mathrm{a}_{8}$ - parameters of the generalized model (11).

Thus each parameter of model (11) makes physical sense.

Not the wave nature of the general model (11) gets in two cases:

1) when a step of discretization of measurements too big in comparison with the period of oscillatory indignation of measured real process (for example, the impulse of the electrocardiogram demands amplitude registration through everyone $0,001 \mathrm{c}$ );

2) when the interval of process of measurements is small in comparison with a half-cycle of oscillatory indignation of the measured indicator (for example, change of global average annual temperature in one point of Earth demands registration for 1000 years and more).

\subsection{Wave Making Models}

The elementary wave dependences are mathematical functions $\sin (\mathrm{x})$ and $\cos (\mathrm{x})$. In the trigonometric law $\cos (\mathrm{x})$ at a value of a variable $\mathrm{x}=0$ rate $\mathrm{y}=\cos (\mathrm{x})$ equal to zero, that is the wave passes always through the beginning of rectangular system of coordinates. Therefore for an abscissa in an interval $(0, \infty)$ the law of a cosine is assumed as a basis. As a result process of identification of steady regularities is facilitated.

In pure form (without empirical coefficients) sine and 
cosine laws (they are mutually reversible) meet in natural processes very seldom. Therefore Euler refused subsequently the hypothesis that any natural processes can be described the sum of functions of a sine and a cosine.

Therefore most idle time according to Euler is the law of wave change of a look

$$
\mathrm{y}=\cos (\mathrm{ax})
$$

In it the parameter of model a becomes activity of influence of a variable $\mathrm{x}$ that was noted for the linear law.

Expression under function of a cosine can be any algebraic law, including with application of the indicative law

$$
y=\cos \left(a x^{b}\right) .
$$

For statistical modeling it is important to receive such parameters of a wave as amplitude of fluctuation and the fluctuation period. Therefore, the original statistical model it is desirable to record with these parameters fluctuations.

Then record of a formula (12) takes a form

$$
y=a \cos \left(\pi x / p_{0.5}\right)
$$

where a - a half of amplitude of oscillatory process, $\pi-\mathrm{a}$ fundamental physical constant (Archimedes's number or space number) which in the program CurveExpert environment is accepted with 18 signs after a comma, $\mathrm{p}_{0.5}$ - a half of the period of oscillatory process (wave number) which in this case (14) constant.

The half-cycle is measured in dimension of an explaining variable that is convenient and evident for identification process. Use of frequency of fluctuation $1 / \mathrm{p}_{0.5}$ is irrational.

The amplitude may vary on sustainable law, similar to the complex dependence can have and the period of oscillation changes.

Therefore we can write down more difficult formula on a design

$$
\mathrm{y}=\mathrm{a}(\mathrm{x}) \cos \left(\pi \mathrm{x} / \mathrm{p}_{0.5}(\mathrm{x})\right)
$$

If the beginning of a wave doesn't coincide with the beginning of coordinates at value $\mathrm{x}=0$, wave shift from zero is considered by additional parameter in statistical model of type

$$
\mathrm{y}=\mathrm{a}_{1} \cos \left(\pi \mathrm{x} / \mathrm{p}_{0.5} \pm \mathrm{a}_{2}\right) .
$$

The initial model (16), as a rule, forms the third component which characterizes infinite-dimensional wave indignation of studied space, terrestrial, ecological, economic or technological process after a trend (the determined part). As well as in table 2, generalization of the wave equations is necessary. Thus the biotechnical law has to be a basic element of the mathematical description of change of amplitude and the fluctuation period.

\subsection{Asymmetric Wavelet}

We adhere to Descartes's concept about need application of the algebraic equation of a general view directly as final mathematical solution of the unknown differential or integrated equations. For such generalization the new class of wave functions [8-15, 19, 24, 29-33] was offered.

To conditions of physical existence of the phenomena and processes asymmetric wavelet-function of a look most fully satisfies

$$
\begin{gathered}
y=\sum_{i=1}^{m} y_{i}, \\
y_{i}=a_{1 i} x^{a_{2 i}} \exp \left(-a_{3 i} x^{a_{4 i}}\right) \times \\
\times \cos \left(\pi x /\left(a_{5 i}+a_{6 i} x^{a_{7 i}} \exp \left(-a_{8 i} x^{a_{9 i}}\right)-a_{10 i}\right),\right.
\end{gathered}
$$

where $\mathrm{y}$ - an indicator (a dependent factor), i - number of the making model (17), $\mathrm{m}$ - number of members in model (17), $\mathrm{x}$ - the explaining variable (the influencing factor), $\mathrm{a}_{1} \ldots \mathrm{a}_{10}$ - the parameters accepting numerical values during structural and parametrical identification in process of increase in coefficient of correlation in process of accumulation of quantity of components of statistical model (17).

In a formula (17) function of a cosine is a link between geometry and algebra and it contains two fundamental physical constants: e (number of time or Napier's number) and $\pi$ (number of space or Archimedes's number). These constants give confidence of identification binding four types of interactions [25].

In most cases for identification of steady biotechnical regularities, because of rather low accuracy of tabular models, the truncated design (on the formula of the period enclosed in trigonometric function or fluctuation frequencies) asymmetric wavelet type is sufficient

$$
\begin{gathered}
y=\sum_{\mathrm{i}=1}^{\mathrm{m}} \mathrm{y}_{\mathrm{i}}, \\
\mathrm{y}_{\mathrm{i}}=\mathrm{a}_{1 \mathrm{i}} \mathrm{x}^{\mathrm{a}_{2 \mathrm{i}}} \exp \left(-\mathrm{a}_{3 \mathrm{i}} \mathrm{x}^{\mathrm{a}_{4 \mathrm{i}}}\right) \cos \left(\pi \mathrm{x} /\left(\mathrm{a}_{5 \mathrm{i}}+\mathrm{a}_{6 \mathrm{i}} \mathrm{x}^{\mathrm{a}_{7 \mathrm{i}}}\right)-\mathrm{a}_{8 \mathrm{i}}\right) .
\end{gathered}
$$

The number $\mathrm{m}$ of members in our examples up to 120 or more. For example, change of relative atomic mass of chemical elements depending on serial number in D. I. Mendeleev's table received model with 92 members [8].

\subsection{Dynamic Range as a Series of Signals}

Physics and Mathematics approach involves understanding dynamic range as a reflection of some composite process or multiple series and parallel occurring natural and/or natural and anthropogenic real processes. For the first time it was succeeded to receive models of many types of series of dynamics on the concept of additive decomposition of any dynamic row on a set of signals.

The signal is a material data carrier. And information is understood by us as an interaction measure. The signal can be generated, but its reception isn't obligatory. So, for example, a number of prime numbers is known some thousands of years, 
but its essence as sets of signals still wasn't opened [19].

Any physical process or its part can be a signal. It turns out that change of a set of unknown signals is known long ago, for example, through ranks of hydrometeorological measurements in many points of a planet. However still there are no statistical models of dynamics of global temperature and other parameters of earth's environment.

Then we can write down any equation of type (18) as a look wavelet-signal

$$
\begin{gathered}
\mathrm{y}_{\mathrm{i}}=\mathrm{A}_{\mathrm{i}} \cos \left(\pi \mathrm{x} / \mathrm{p}_{\mathrm{i}}-\mathrm{a}_{8 \mathrm{i}}\right), \\
\mathrm{A}_{\mathrm{i}}=\mathrm{a}_{1 \mathrm{i}} \mathrm{x}^{\mathrm{a}_{2 \mathrm{i}}} \exp \left(-\mathrm{a}_{3 \mathrm{i}} \mathrm{x}^{\mathrm{a}_{4 \mathrm{i}}}\right), \mathrm{p}_{\mathrm{i}}=\mathrm{a}_{5 \mathrm{i}}+\mathrm{a}_{6 \mathrm{i}} \mathrm{x}^{\mathrm{a}_{\mathrm{ii}}},
\end{gathered}
$$

where $A_{i}$ - amplitude (half) of a wavelet (axis $y$ ), $p_{i}-a$ half-cycle of fluctuation (axis $\mathrm{x}$ ).

On a formula (19) with two fundamental physical constants e (Napier's number or number of time) and $\pi$ (Archimedes's number or number of space) the quantized wavelet signal is formed from within the studied phenomenon and/or process.

The concept of a wavelet signal allows to abstract from physical sense of statistical ranks of measurements (generally not only dynamic ranks) and to consider their additive decomposition on separate components in a look wavelets.

\section{Example of Statistical Modeling}
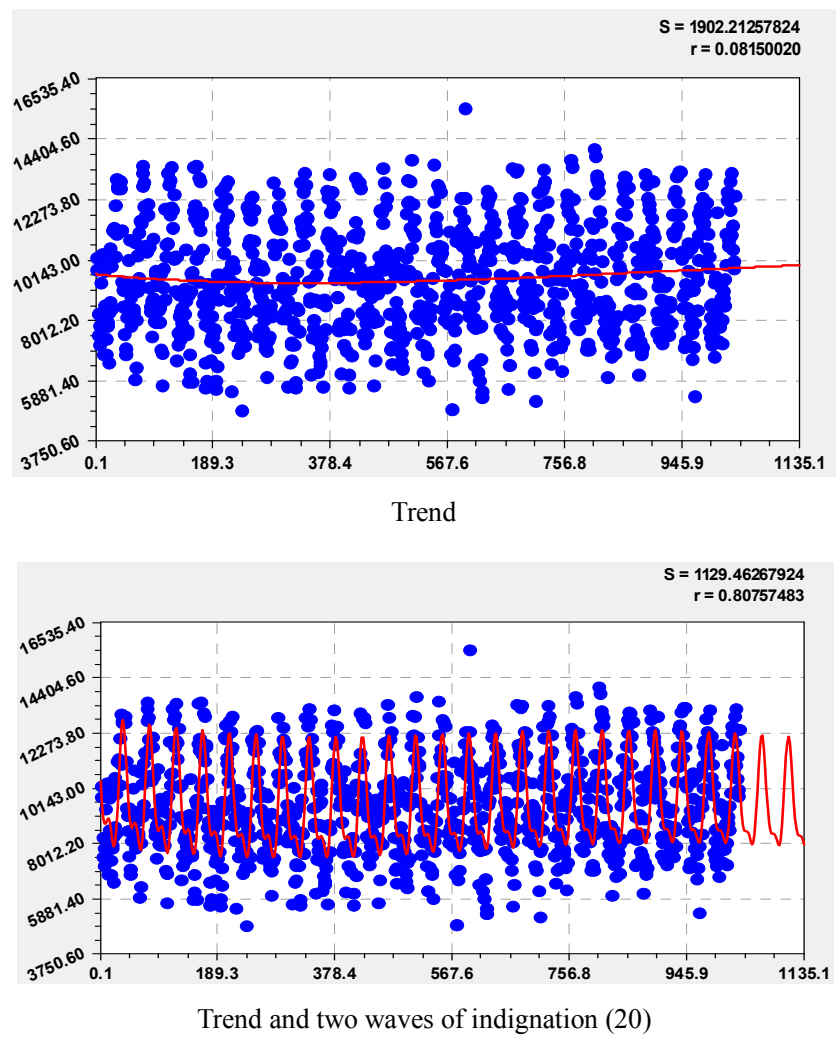

Figure 1. Dynamics of quantity of increments of hour impulses of alpha decay on hours in 43 days of a solar eclipse.

In the r040309.dat [7] array there are 3808482 supervision on measurements of a solar eclipse (data were kindly provided the prof. S.E. Shnol).

They are received by every second measurements of alpha activity of a sample ${ }^{239} \mathrm{Pu}$. We will accept for the beginning of days on computation of time of many religions of 5 o'clock in the morning. Then the whole days begin since March 10, 2005 at 5 o'clock in the morning. Therefore from the r040309.dat array it is excluded the first 54314 points and it is received 43 full days. The last values after 43 days also excluded.

In total 3715200 supervision in the new r040309utozn.dat array or $97,55 \%$ of an initial data file were considered. Then every second data were summarized on increasing time scales. Possibility of record of number in memory of the computer is thus considered: there can be a failure of the program CurveExpert-1.40 environment at excess of value of the sum more $2 \cdot 10^{5}$.

Further we will give an example of identification of four-membered model of hourly dynamics of alpha decay [13, $14,27,29,30]$. In total 43 days of measurements give hourly dynamics in time in $43 \times 24=1032$ hours (fig. 1).

Time $t_{\mathrm{u}}$ in hours in all 43 days of measurements influences on the general formula

$$
\begin{aligned}
& \mathrm{I}_{\mathrm{q}}=\mathrm{I}_{\mathrm{q} 1}+\mathrm{I}_{\mathrm{q} 2}+\mathrm{I}_{\mathrm{ч} 3}+\mathrm{I}_{\mathrm{q} 4}, \\
& I_{\text {ч1 }}=9864,1280 \exp \left(-0,00032887 t_{\text {ч }}\right) \text {, } \\
& \mathrm{I}_{\text {ч2 }}=8,94831 \cdot 10^{-5} \mathrm{t}_{\mathrm{q}}{ }^{2,70681} \exp \left(-0,00011920 \mathrm{t}_{\mathrm{u}}{ }^{1,37029}\right) \text {, } \\
& \mathrm{I}_{\mathrm{q} 3}=\mathrm{A}_{1} \cos \left(\pi \mathrm{t}_{\mathrm{u}} / \mathrm{p}_{1}+0,88335\right), \\
& A_{1}=2012,6762 \exp \left(-3,76974 \cdot 10^{-5} t_{\text {ч }}\right), p_{1}=21,46911 \text {, } \\
& \mathrm{I}_{\mathrm{q} 4}=\mathrm{A}_{2} \cos \left(\pi \mathrm{t}_{\mathrm{\varphi}} / \mathrm{p}_{2}-4,03684\right), \\
& A_{2}=1058,4475 \exp \left(-0,00034297 t_{\mathrm{q}}\right), p_{1}=10,73986 \text {. }
\end{aligned}
$$

The coefficient of correlation of model (20) is equal 0.8076 and this value of an indicator of narrowness of communication according to table 3 refers model (20) to category of strong factorial communications.

The trend in the form of the law of death shows slow recession with coefficient of correlation only 0.0815 . As a result it becomes clear that the existing assessment of processes only on a trend at once yields negative result as as if communication between two factors doesn't exist. Therefore according to the existing theory of approximation the conclusion would be drawn on lack of factorial communication.

According to table 3 we receive that value of coefficient of correlation $0.0815<<0.3$. But, as considerably from drawing the 1 , first infinite-dimensional fluctuation gives coefficient of correlation 0.7325 . And the second fluctuation I received a measure of narrowness of communication 0.4914 .

Both wavelet are infinite-dimensional because amplitude changes under the law of exponential death (recession). But thus the fluctuation half-cycle constant also is equal, respectively 21.46911 and 10.73986 hours. 
Then the periods of fluctuation will be equal $2 \times 21.46911$ $\approx 42.94$ and 21.48 hours. The constant wave of indignation has the second twice less, than at the fluctuation period at the first wave. But both of them don't coincide with a cycle of the address of Earth round themselves in 24 hours.

Thus, the models only determined together with the wave equations can give the correct and authentic mathematical description of the physical processes happening in the nature. Thus by us it was proved that the radioactivity of disintegration of plutonium depends on interactions of the Sun, Earth and the Moon.

\section{Conclusions}

We proved possibility of a solution of the problem of development of methods of calculus of variations (Hilbert's 23rd problem) in its separate part (having excluded abstract mathematics), in relation to statistical modeling of tables according to measurements. Hilbert's bricks which are reduced to the biotechnical law were for this purpose received.

They allow to design the generalized algebraic equation according to Descartes in the form of the sum asymmetric wavelets with variables amplitude and the fluctuation period.

The methodology and technology of identification of any natural phenomena and processes is created. Thus the casual choice of the equations is excluded and replaced with conscious selection of a design of statistical model by way of accumulation of the sum of members in the form of a set asymmetric wavelets with variables amplitude and the fluctuation period.

Therefore on the computer only the stage of parametrical identification of the increased sum of members in the form of asymmetric wavelet signals is realized. However the program CurveExpert environment for such identification approaches a little: process very labor-consuming at selection of a design of certain members of model. Thus the program CurveExpert environment is limited by number of at the same time identified model parameters. Therefore according to our scenarios it is necessary to create specially the new program environment for its application on supercomputers.

\section{References}

[1] G.V. Brummelen, M. Kinyon. Mathematics and the Historian's Craft. The Kenneth O. May Lectures. 2005. Springer Science, Business Media, Inc. Library of Congress Control Number: 2005923503. bok\%3A978-0-387-28272-5.pdf.

[2] L. Corry. Archive for History of Exact Sciences. Chapter: David Hilbert and the Axiomatization of Physics (1894-1905). Springer-Verlag, 1997. P.83-198. DOI 10.1007/BF00375141.

[3] L. Corry. Modern Algebra and the Rise of the Mathematical Structures. Chapter 3. David Hilbert: Algebra and Axiomatics. Birkhäuser Basel, 2004. P.137-182. DOI 10.1007/978-3-0348-7917-0 4.

[4] Invariant theory. Algebraic number fields. Axiomatic. Integral equations. Physics. http://www.ega-math.narod.ru/Reid/Weyl.htm \# ch1.
[5] Progress in Mathematics. Volume 280. Series Editors H. Bass, J. Oesterle, A. Weinstein // Liaison, Schottky problem and Invariant Theory. Remembering Federico Gaeta. Maria Emilia Alonso, Enrique Arrondo, Raquel Mallavibarrena, Ignacio Sols, Editors. Birkhauser. 2010 / Springer Basel AG. bok\%3A978-3-0346-0201-3.pdf.

[6] D.E. Rowe. Hilberrs Early Career: Encounters with Allies and Rivals. THE MATHEMATICAL INTELLIGENCER 9, 2005. Spnnger Science+Business Media. Inc. art\%3A10.1007\%2FBF02984817.pdfHilberrs.

[7] S.E. Shnoll. Kosmofysiska faktorer i slumpmassiga processer. Stockholm, Svenska fysikarkivet, 2009. 388 p.

[8] P.M. Mazurkin. A statistical model of the periodic table of chemical elements D.I. Mendeleev. Yoshkar-Ola: MarSTU, 2006. 152 p.

[9] P.M. Mazurkin. Asymmetric entire series prime numbers // Collection of scientific works Sword,. Issue 3. Volume 4. Odessa: KUPRIENKO SV, 2013. 313-0468. C.38-42.

[10] P.M. Mazurkin. Asymmetric Wavelet Signal of Gravitational Waves. Applied Mathematics and Physics, vol. 2, no. 4 (2014): 128-134. doi: 10.12691/amp-2-4-2.

[11] P.M. Mazurkin. Block Structure of a Number of the Integers Prime. Applied Mathematics and Physics, vol. 2, no. 4 (2014): 135-145. doi: 10.12691/amp-2-4-3.

[12] P.M. Mazurkin. Chaos and Order in the Integers Primes. Applied Mathematics and Physics, vol. 2, no. 4 (2014): 146-156. doi: 10.12691/amp-2-4-4.

[13] P.M. Mazurkin. Dynamics of alpha activity of pattern ${ }^{239} \mathrm{PU}$ in different time scales // SCIENCE AND WORLD: International scientific journal, 2013. № 2(2). P.20-26.

[14] P.M. Mazurkin. Dynamics of alpha activity ${ }^{239} \mathrm{PU}$ in stages of solar eclipse // SCIENCE AND WORLD: International scientific journal, 2013. № 4(4). P.20-26.

[15] P.M. Mazurkin. Dynamics of Russian inventions // Intellectual property. Industrial property. 2014. №2. P.14-21.

[16] P.M. Mazurkin. Factor analysis of the technical level of sibgle-bucket hydraulic excavators // International Journal of Engineering and Innovative Technology (IJEIT), Volume 3, Issue 9, March 2014. P.84-92.

[17] P.M. Mazurkin. Forest agricultural Russian and world dynamics of forest. Yoshkar-Ola: MarSTU, 2007. 334 p.

[18] P.M. Mazurkin. Geoecology: Patterns of Modern Natural Science. Yoshkar-Ola: MarSTU, 2006. 336 p.

[19] P.M. Mazurkin. Identification of statistical stable patterns // Science and World. № 3(3). 2013. P.28-33.

[20] P.M. Mazurkin. Increment Primes. American Journal of Applied Mathematics and Statistics, vol. 2, no. 2 (2014): 66-72. doi: 10.12691/ajams-2-2-3.

[21] P.M. Mazurkin. Patterns of primes. Germany: Palmarium Academic Publishing, 2012. 280 p.

[22] P.M. Mazurkin. Proof the Riemann Hypothesis. American Journal of Applied Mathematics and Statistics, vol. 2, no. 1 (2014): 53-59. doi: 10.12691/ajams-2-2-1. 
[23] P.M. Mazurkin. Series Primes in Binary. American Journal of Applied Mathematics and Statistics, vol. 2, no. 2 (2014): 60-65. doi: 10.12691/ajams-2-2-2.

[24] P.M. Mazurkin. Solution of the twenty third problem of Hilbert // Interdisciplinary research in the field of mathematical modeling and computer science. Proceedings of the 3-rd scientific and practical internet-conference. Ulyanovsk: SIMJET, 2014. P 269-277.

[25] P.M. Mazurkin. Stable Laws and the Number of Ordinary. Applied Mathematics and Physics, vol. 2, no. 2 (2014): 27-32. doi: 10.12691/amp-2-2-1.

[26] P.M. Mazurkin. Statistical modeling. Heuristic-mathematical approach. Yoshkar-Ola: MarSTU, 2001. 100 p.

[27] P.M. Mazurkin. Statistical Sociology: a tutorial. Yoshkar-Ola: MarSTU, 2006. 184 p.

[28] P.M. Mazurkin. Statistical Econometrics: a tutorial. Yoshkar-Ola: MarSTU, 2006. 376 p.

[29] P.M. Mazurkin. The wavelet analysis of alpha activity ${ }^{239} \mathrm{PU}$ of the solar eclipse // SCIENCE AND WORLD: International scientific journal, 2014. № 1(5). P.94-104.
[30] P.M. Mazurkin. Wavelet Analysis of a Number of Prime Numbers. American Journal of Numerical Analysis, vol. 2, no. 2 (2014): 29-34. doi: 10.12691/ajna-2-2-1.

[31] P.M. Mazurkin. Wavelet analysis of hour increments of alpha activity ${ }^{239} \mathrm{PU}$ at the maximum of the solar eclipse // SCIENCE AND WORLD: International scientific journal, № 2 (6), 2014, Vol. I. P.46-55.

[32] P.M. Mazurkin. Wavelet analysis of hour increments of alpha activity ${ }^{239} \mathrm{PU}$ after the solar eclipse // SCIENCE AND WORLD: International scientific journal, № 3 (7), 2014, Vol. I. P.31-40.

[33] P.M. Mazurkin. Wavelet analysis of the crisis ruble exchange rate dynamics // Interdisciplinary research in the field of mathematical modeling and computer science. Proceedings of the 3-rd scientific and practical internet-conference. Ulyanovsk: SIMJET, 2014. P 260-268.

[34] P.M. Mazurkin, A.S. Filonov. Mathematical modeling. Identification single factor statistical regularities. Yoshkar-Ola, Mari State Technical University, 2006. 292 p. 